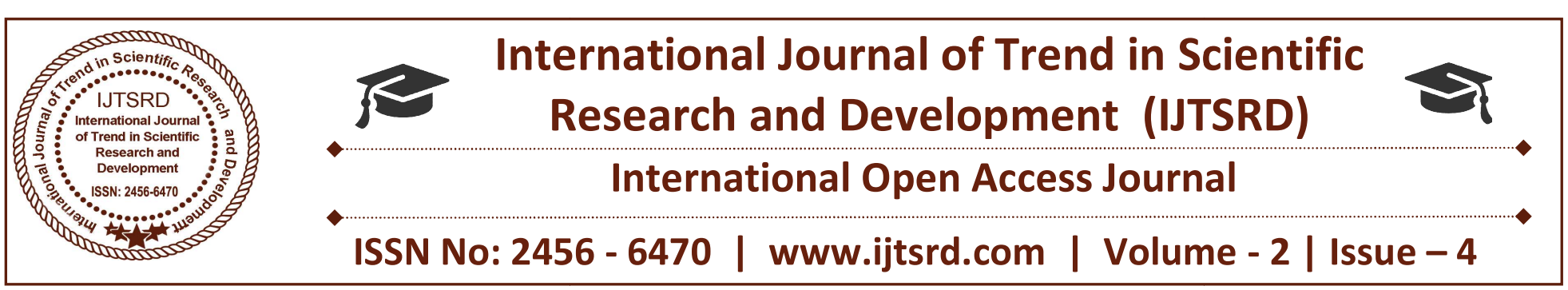

\title{
Anti - Theft Vehicle Device
}

\section{Simmi Dutta, Monika Abrol, Arjun Kapoor, Karamjeet Singh, Rahul Kumar \\ B.E , Computer Engineering Department, GCET, Jammu, India}

\begin{abstract}
Nowadays rate of vehicle theft is very high all through the world and the situations are even worse in developing country. The existing technologies for vehicle security have a number of limitations including high false alarm rate, easy deactivation and high cost. Therefore, protection of vehicles with an intelligent, reliable, effective and economical system is extremely essential for public vehicles. So. in order to bring a solution for this problem the proposed system can be implemented. Anti-Theft Vehicle System is installed in the vehicle, to track the place of the vehicle and to lock the engine motor, thereby controlling it. ${ }^{[1]}$
\end{abstract}

Index Terms- Vehicle Tracking, GSM Module, GPS Module, Locking, Microcontroller, Fire Detector

\section{INTRODUCTION}

Due to fact that the cases of vehicle theft increases day by day, an efficient security mechanism is needed for our vehicle in order to protect it from robbery. There exists a lot of security mechanisms provided by the manufacturer in addition to the extra technologies available in the market, but still, there exists some security gaps where these technologies don't prevent a vehicle from theft, don't assist to recover it and don't allow the users to know the status of their vehicles. They neither permit the owner to communicate with the vehicle, even if the owner is certain that his vehicle was stolen nor do they allow the owner to control the car. The available security systems in the market contain either a locking system or a GPS based tracking system. The problem with the normal locking system is that an expert can easily unlock the vehicle if he has the necessary tools. These systems also come with a high implementation and maintenance cost. Most of these systems need further updates which cost more money. ${ }^{[2]}$
Currently the inbuilt security system is provided only for higher editions by most of the manufactures. The implementation of additional security system cost a large amount of money which cannot afforded by a normal user.

\section{PROPOSED SYSTEM}

The proposed security system in this paper is designed to track, monitor and stop the vehicle .Antitheft Vehicle Device aims to give security to all the vehicles. This new technology is basically an embedded system that is fitted on to the vehicle in such a manner that it is not visible to anyone who is inside or outside of the vehicle. Thus, it is used as a covert unit which sends the location data to the monitoring unit i.e.- owner's mobile, on demand. The proposed system works using GPS and GSM technology for tracking and relays for controlling (locking) the vehicle. All that the user have to do is install this embedded system in his vehicle. Once this system is installed in the vehicle, the user will have to set his number in the program. The security system is an integration of existing technology GPS that is currently used in location tracking and modern communication technology SMS. SMS is the easiest way that is used widely for communication purposes because they are inexpensive, convenient and messages can be transmitted and received with high reliability. This combination of GPS and GSM technologies will provide effective, real time vehicle location, and reporting of the status to the owners. It will let owners know, about the vehicle's current location just by sending an sms, where was it and for how long it was present there using GPS. In the proposed system, if the owner feels that his car is used by an illegitimate user then he will send a message to GSM module to switch off the car. In response to this message the speed of the car engine 
will slow down gradually until it gets turned off. Once it gets turned off, the doors get locked. Thus, the thief cannot escape and police can be informed simultaneously. This is how theft control will be implemented. ${ }^{[3]}$

\section{BLOCK DIAGRAM}

In this Project it is proposed to design an embedded system which is used for tracking and positioning of any vehicle by using Global Positioning System (GPS) and Global system for mobile communication (GSM).

In this project, as shown in figure 1, 8052 microcontroller is used for interfacing to various hardware peripherals. An 8052 microcontroller is interfaced serially to a GSM Modem and GPS Receiver. A GSM modem is used to send the position (Latitude and Longitude) of the vehicle from a remote place. The GPS modem will continuously give the data i.e. the latitude and longitude indicating the position of the vehicle. The GPS modem gives many parameters as the output, but only the NMEA data coming out is read and displayed on to the LCD. The same data is sent to the mobile at the other end from where the position of the vehicle is demanded. An EEPROM is used to store the data received by GPS receiver. The hardware interfaces to microcontroller are LCD display, GSM modem and GPS Receiver. Fire detector are used for detecting different types of problem encountered in the vehicle such as theft, accident, fire warning etc. In any of these cases messages will be automatically send to the intended receiver.

When a request by user is sent to the number at the modem, the system automatically sends a return reply to that particular mobile indicating the position of the vehicle in terms of latitude and longitude. In case, if the car is hit by an accident or it catches fire, or suddenly the temperature starts to rise the, the Fire Sensor will send the alarm message to the fire department as well as to owner to take some action at the earliest.

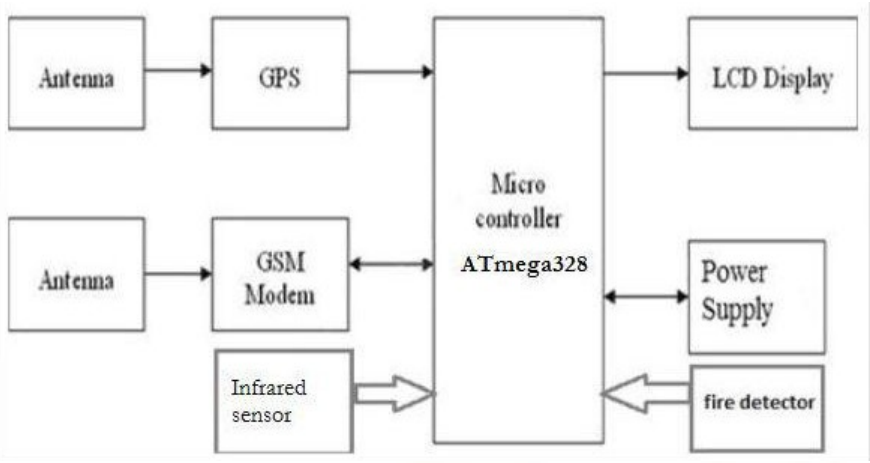

Fig1. Block diagram of Anti-Theft vehicle Device

\section{COMPONENTS USED}

Main hardware components used in this format are listed below:-i. Microcontroller ATMega328(Arduino Uno)
1) DC Power Supply
2) $16 \times 2 \mathrm{LCD}$
3) GSM MODEM SIM $800 / 900 / 900 \mathrm{~A}$
4) GPS MODULE L80-m39
5) Flame Detector
6) Relays $(10 \mathrm{~A} / 12 \mathrm{~V})$
7) Breadboard

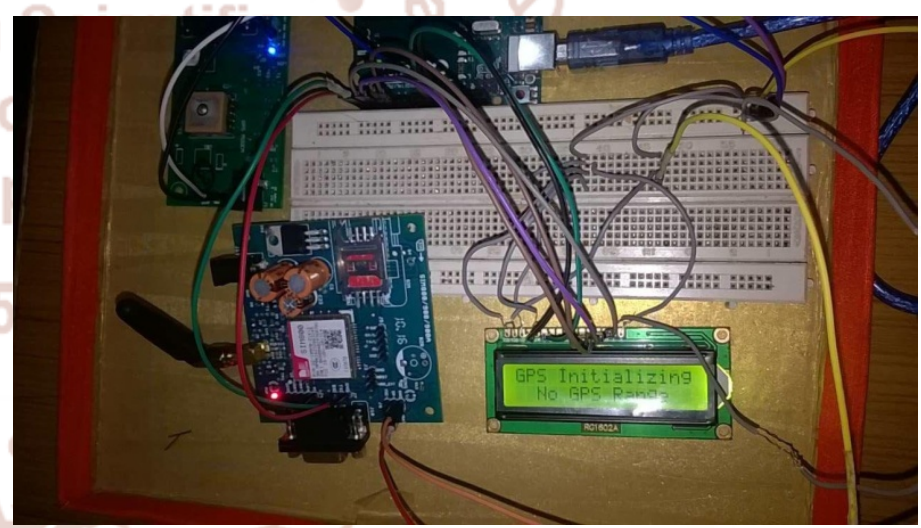

Fig 4. Actual project

\section{IMPLEMENTATION DETAILS}

The system has two main units; the first is security unit which is embedded in the vehicle. This unit consists of: a GSM modem, GPS receiver, control relay and Microcontroller as shown in Fig.2.The microcontroller will send SMS directly to the owner to confirm that number. NC control relay contacts are connected with the hot line that powers the fuel pump and ECM. The microcontroller can send a signal to the relay to cut off the power, when received SMS contains code ("STOP VEHICLE") from owner mobile to stop it. The GPS Receiver retrieves the location information from satellites in the form of latitude and longitude readings in real- 
time. The Microcontroller processes the GPS information and transmits it to the user using GSM modem by SMS whenever the user asks that from the system by sending SMS. The Microcontroller also reads engine parameters from vehicle data port (OBD-II) and sends them to the second module in the same SMS. The second module is a recipient GSM that is basically a mobile. It can be a laptop or a PC. The modem receives the SMS that includes GPS coordinates, temperature of the engine, the mobile number of the message sender so as to confirm that the phone number is legal or illegal to access the system; if the phone number is legal the system will turn off the vehicle. When a request by user is sent to the number at the modem, the system automatically sends a return reply to that particular mobile indicating the position of the vehicle in terms of latitude and longitude. The owner then can locate the exact position of the vehicle and can navigate the track of the moving vehicle on Google maps, corresponding to the latitude and longitude values received. The fire detector circuit in it is used to detect fire in the vehicle, if the temperature inside the vehicle goes above a certain limit then a warning will be automatically send to the emergency number as well as the intended receiver. [6]

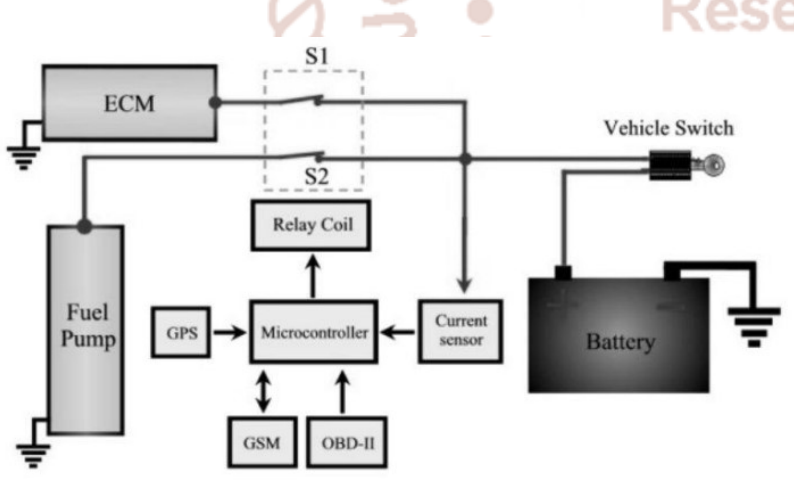

Fig. 2. The structure of main unit of anti-theft system

Now it is the time to articulate the research work with the software used in it.

\section{B.Software Simulation}

Arduino is an open-source electronics platform based on easy-to-use hardware and software. Arduino boards are able to read inputs - light on a sensor, a finger on a button, or a Twitter message - and turn it into an output - activating a motor, turning on an LED, publishing something online. ${ }^{[7]}$

The code you write for the arduino is executed by this controller. And it is directly connected to the $\mathrm{I} / \mathrm{O}$ pins.
The controller is programmed via the TX, RX pins connected to the USB to serial controller and contains boot loader code. It can also be programmed directly via the ICSP pins.

\section{KEY FEATURES \\ Some basic features of this security system are :-}

1) User can access the system to get the information about vehicleat any time whenever needed.

2) Vehicle system will send the information about vehicle automatically to Monitoring system . This results in medical help in case of accident and in case of theft.

3) User can stop the vehicle engine, whenever theft of vehicle by using Relays.

4) It includes a flame detector which alerts the owner whenever temperature of the car rises above the threshold temperature limit.

5) It can be used for trucks carrying valuable goods, to keep track of the status of delivery and location of the truck at all times.

6) You can also use it to keep tab on your driver. It reduces vehicle abuse and ultimately results in significant cost-savings for individuals, fleet owners and the like. ${ }^{[4]}$

\section{Ease of Use :-}

When a User want to send a secure message to the another user than simply it only have to type the text on key board that it wants to transmit. It is very secure because only authorized user can actually access the actual message other user which want to hack or interpret the signal, gets only encrypted message and for decryption they want exact codes used in encryption. Only authorized receiver knows about the actual decryption codes and only able to decrypt it. So it is very much secure and easy method for message transmission. ${ }^{[5]}$

\section{RESULTS}

If the user loses his sight of the vehicle, then to find the exact location of the vehicle, he just has to send a message to the microcontroller coded as - "Track Vehicle". The microcontroller will send the latitude and longitude values to the user, as shown below. If the user wants to stop the vehicle at the remote location then, on sending the message - "Stop Vehicle", the engine of the vehicle will be turned off. 
Received Track Vehicle

Vehicle Tracking Alert:

Your Vehicle Current Location is:

Latitude:3244.3456

Longitude: $\underline{07449.8778}$

http://maps.google.com/?q=your+query

Please take some action soon.

Thankyou

\section{Trext message}

If the vehicle catches fire, the microcontroller will send an alert message to the user as well as to the emergency number(FIRE CONTROL DEPTT) to alert them about the fire.

\section{CAUTION CAUTION CAUTION}

Car Caught With fire take some action immediately

Get the location Immediately by sending

(Track Vehicle)
3) Instead of a Microcontroller we can use a CPLD chip since the CPLD incorporates many more features than a Microcontroller. VLSI/VHDL can be used for CPLD programming.

4) A fingerprint scanner can be incorporated on the steering wheel of the vehicle to allow only authorized user to access the vehicle.

5) A system for detecting behavior of driver can also be implemented. A camera can be placed besides rear view mirror to check the behavior of the driver reduced until it completely stops avoiding major mishaps.

6) A VB application program can be made and given to all the police stations so that the police can keep track of all the vehicles. Especially, for all the cab drivers, if this system is inserted in all the cabs, then it can add to the safety of girls as the police can easily trace the vehicle and prevent the victims from getting hurt or becoming prey to any mishaps.

7) We can control the vehicles using an app which receives the SMS from the microcontroller and which sends SMS to the microcontroller. The app can also be used to lock, unlock the vehicle, to start and switch off the vehicle. This app can also be used for vehicle scheduling which would in turn save a lot of time of drivers by letting them know the route with minimum.

\section{CONCLUSION}

In this project, we have proposed a novel and low cost method of vehicle tracking and locking systems used to track the theft vehicle by using GPS and GSM technology. When the theft is identified, the responsible people send SMS to the microcontroller, then issue the control signals to stop the engine motor. After that all the doors locked. To open the doors or to restart the engine authorized person needs to enter the passwords. In this method, easy tracking and locking of the vehicle place is possible.

\section{FUTURE SCOPE}

This project is very basic.We can add many features and facilites to this project to enhance its utility.Some of them are :

1) For Lane Tracking purpose, a front camera can be attached to the vehicle.

2) Long range IR sensors can also be used to avoid vehicle collision.

\section{REFERENCES}

1) S.Sonika, Dr.K.Sathiyasekar, S.Jaishree, (2014), Intelligent Accident Identification System using GPS, GSM modem, IJARCCE, Vol 3, Issue 2, pp 5487-5489.

2) Kai-Tai Song, Chih-Chieh Yang, of National Chiao Tung University, Taiwan, "Front Vehicle Tracking Using Scene Analysis", Proceedings of the IEEE International Conference on Mechatronics \& Automation 2005.

3) Pau Muñoz-Benavent, Leopoldo Armesto, Vicent Girbés, J. Ernesto Solanes, Juan Dols, Adolfo Muñoz, and Josep Tornero, "Advanced Driving Assistance Systems for an Electric Vehicle" AUSMT, Vol 2, No 2, 2013, "Cloud Computing Based Vehicle Tracking Information Systems", ISSN: 2229 - 4333 ( Print) | ISSN: 0976 8491 (Online ) IJCST. 
International Journal of Trend in Scientific Research and Development (IJTSRD) ISSN: 2456-6470

4) Albert Alexe, R.Ezhilarasie Vol. 2, Issue 1, March 2011 e 9, September 2014, pg 244-258.

5) M. Abhinaya et al, "Intelligent vehicle control using wireless embedded system in transportation system based on GSM and GPS technology", IJCSMC, Vol.3, Issue 2, Issue 4, October 2012.

6) Swami Supriya et al's "An intelligent vehicle control and monitoring using arm", International journal of engineering and innovative technology (IJEIT), Volume

7) Ashwini et al "Design of intelligent traffic control system using ARM", International Journal of Advance Research in Computer Science and Management Studies, Volume 1, Issue 6, November 2013. 